\title{
Principles of Curriculum Design and Construction Based on the Concepts of Educational Neuroscience
}

\author{
Chandana Watagodakumbura ${ }^{1}$ \\ ${ }^{1}$ School of Engineering and Technology, Central Queensland University, Melbourne, Australia \\ Correspondence: Chandana Watagodakumbura, School of Engineering and Technology, Central Queensland \\ University, 120, Spencer St, Melbourne, VIC, 3000, Australia. Tel: 61-3-9616-0555. E-mail: \\ c.watagodakumbura@cqu.edu.au
}

Received: February 28, 2017

Accepted: March 10, $2017 \quad$ Online Published: March 15, 2017

doi:10.5539/jel.v6n3p54

URL: http://doi.org/10.5539/jel.v6n3p54

\begin{abstract}
With the emergence of a wealth of research-based information in the field of educational neuroscience, educators are now able to make more evidence-based decisions in the important area of curriculum design and construction. By viewing from the perspective of educational neuroscience, we can give a more meaningful and lasting purpose of leading to human development with enhanced consciousness or wisdom as the goal of a curriculum. We can better decide on the essential contents of a curriculum that is carried out within a limited time, using the emerging and validating information. Knowledge of educational neuroscience can also be used effectively for instructional design or conveying important messages to learners in the learning support material provided. Further, educators can be better directed in forming appropriate assessment so that learners are prepared for active and deep engagements in the teaching-learning process developing the skills of independence and discovery learning. Educational practitioners, as well as policy-makers, can also promote inclusive practices by directing, designing and constructing a curriculum appropriately especially taking into consideration the characteristics of right cerebral hemispheric oriented visual-spatial or gifted learners. Overall, education professionals can be benefited immensely to take more informed decisions in the process of curriculum design and construction by embracing emerging educational neuroscience principles.
\end{abstract}

Keywords: curriculum design and construction, educational neuroscience, human development, education practitioners and policy makers, assessment, wisdom and consciousness

\section{Introduction}

Curriculum design or construction is an important task educators undertake to enable learners a lasting and useful experience at the end of carrying out the curriculum. Educational neuroscience is a field that has attracted the interest of educational professionals more elaborately in the recent past. It provides us with some useful knowledge about the human brain and how the structures of the brain help human beings in learning. In fact, when we refer to the term "learning", from the perspective of neuroscience, it is essentially about building neural networks of knowledge. Consequently, by making use of the emerging notions and principles of educational neuroscience, educators can improve their pedagogical practices immensely so that enhanced learning towards higher levels of human development can be achieved. In this regard, there is no difference when it comes to designing and constructing a curriculum as part of a teaching-learning process. For example, we can define the purpose of a curriculum more meaningfully taking into consideration the development of human brain through learning in a lifelong manner. What contents to be included in a curriculum, improving the instructional design, making a curriculum more inclusive, valid and fair are some of the areas that educational neuroscience can provide useful research findings for us to be more informed. In this article, we discuss numerous ways curriculum designers and constructors can rely on knowledge from educational neuroscience. In sections two and three, we present the essential background information related to neuroscience, as done in other similar work (Watagodakumbura, 2015c, 2015d), so that the readers can digest the rest of the article more comfortably. We present much practical guidance for designing and constructing curricula based on the input from educational neuroscience in section four. 


\section{Introduction to Primarily Neuroscience-Based Concepts That Relate to Learning and Curriculum Design}

\subsection{Basic Structure of the Human Brain}

Mainly there are three layers of the brain, from bottom to top: the reptilian brain, mammalian brain and neocortex (Baars \& Gage, 2010; MacLean, 1967). The reptilian brain is the oldest layer of the brain; it is composed of the brain stem, the structures that dominate in the brains of snakes and lizards. This part of the brain controls survival activities such as breathing, heart rate and balance. The mammalian brain is layered over the reptilian brain, and consists of a system of brain parts called the limbic system. The constituents of the limbic system include the amygdala, hippocampus and hypothalamus. The limbic system plays a major role in human emotions. The third layer of the brain is the neocortex or primate brain, which is the most recent addition to our brain. It consists of the wrinkled covering of cerebral hemispheres - the left and right. The neocortex plays a major role in cognitive, linguistic, motor, sensory and social abilities. It gives considerable flexibility in creativity in adapting to changing environments. The neocortex is densely interconnected with the limbic system and controls the expression of emotions.

The neocortex has four major lobes, namely, the frontal lobe, parietal lobe, temporal lobe and occipital lobe. One significant feature of the brain structure is brain localisation. That is, the brain is composed of many functionally specialised regions (Luria, 1976; Geschwind, 1979; Edelman \& Mountcastle, 1978). There are about 100 Brodmann areas, so to speak, now recognised in the neocortex. The four lobes of the neocortex and their processes are intricately intertwined with each other. Further, the neocortex, which is vital for cognitive functions, interacts constantly with major so-called satellite organs such as the thalamus, basal ganglia, cerebellum, hippocampus and limbic regions.

It is of special interest to know that frontal lobes are referred to as the organ of civilisation. The role the frontal lobes play in cognition is uniquely human and without their development civilisation could never have arisen (Fuster, 1997; Goldberg, 2001; Ingvar, 1985; Luria, 1966). They are crucial for all higher-order purposeful behaviours such as identifying the objective, projecting the goal, forging plans to reach it, organising how such plans can be carried out and monitoring and judging the consequences. Further, frontal parts of the brain become active when resolving conflicting conditions. A correlation has also been identified between frontal activation and longer reaction time and sense of subjective effort. In summary, the frontal lobe, or more specifically the Pre-Frontal Cortex (PFC), is used for human activities such as language, thought and executive control of higher-order processes and connect directly with every distinct functional unit of the brain (Nauta, 1972). This connectivity allows PFC to coordinate and integrate the functions of other brain structures.

\subsection{Brain Lateralisation}

The ability of certain areas of the brain to perform unique functions is known as cerebral specialisation. If the activity is mainly limited to one hemisphere, it is called cerebral lateralisation. Research studies show that the right and left hemispheres of the brain have distinctly different functions that are not readily interchangeable (Sperry, 1966). The left hemisphere processes input in sequential and analytical manner, is time sensitive, generate the spoken language, does arithmetic operations, recognise words and numbers (as words), active in constructing false memories, better at arousing attention to deal with outside stimuli. The right hemisphere processes inputs more holistically and abstractly, is space sensitive, interprets language through gestures, facial movements, emotions, and body language, does relational and mathematical operations, recognises faces, places, objects and music, more truthful in recall, put events in spatial patterns, better in internal processing, gathers information more from images than from words and look for visual patterns (Gazzaniga, 1998a, 1998b; Gazzaniga, Ivry, \& Mangun, 2002; Semenza et al., 2006; Sweeney, 2009).

Further, the left and right hemispheres are found to be physically different. The left hemisphere has more grey matter, while the right hemisphere has more white. That is, the left hemisphere's more tightly packed neurones are better able to handle intensely detailed work, while the right hemisphere's white matter contains neurones with longer axons that can connect with modules farther away. These long-range connections help the right hemisphere to come up with broad but rather vague concepts, explaining the association with creativity. However, one of the interesting features of the human brain is that it can integrate disparate activities taking place in specialised areas into a unifying whole. In fact, the two cerebral hemispheres are connected by the largest fibre bundle in the brain known as the corpus callosum. 
Despite this significant revelation, it is widely observed and accepted that educational institutes are predominantly left-hemispheric oriented with emphasis on structured environments that run to specific time schedules, favouring facts and rules over patterns and predominantly following verbal instructions.

\subsection{Types of Memory}

Human memory (Squire, 2004, 2009; Baars \& Gage, 2010) can be defined as a lasting representation that is reflected in thought, experience, and behaviour. It can be divided into two main types: explicit and implicit. Explicit memory refers to the memory with conscious awareness, and the individual can declare its existence and comment on its content either verbally or non-verbally (Cohen \& Squire, 1980; Ryle, 1949). Consequently, such memories are known as declarative memories. On the other hand, implicit memory is not accompanied by the conscious awareness that one has a memory; the existence of implicit memory is inferred only from the effects it has on behaviour. Further, implicit memories may be retained without an intention to remember and accessed commonly by priming tasks (Banaji \& Greenwald, 1995; Curran, 2001; Knowlton et al., 1996).

Explicit or declarative memory can be further divided into two types: episodic (autobiographical) memory and semantic memory (Tulving, 1972, 1985). Episodic memory refers to memories that have a specific source in time, space and life circumstances. In contrast, semantic memories involve facts (or high-level concepts and generalisations) about us, the world, and other knowledge that we share within a community and are independent of the spatial and temporal context in which they were acquired. Further, episodic memories are remembered consciously and susceptible to forgetting while semantic memories give a feeling of knowing rather than a fully conscious recollection and less susceptible to forgetting. Initially, memories are episodic and context dependent, and over time they are transformed into semantic memories (Penfield \& Milner, 1958).

Another categorisation of human memory is the division into the two types referred to as working memory (Baddeley, 2000; Baddeley \& Hitch, 1974; Cowan et al., 2005) and long-term memory (Dudai, 2004; LeDoux, 1996; Lees et al., 2000; McGaugh, 2000). Working memory is defined as the set of mental processes holding limited information in a temporarily accessible state in service of cognition. The Pre-Frontal Cortex (PFC) seems to play an important role in working memory processes, and temporal and prefrontal regions of the cortex appear to involve in working storage. Long-term memory, on the other hand, can be large quantities of information stored on a more permanent or longer duration basis. The neocortex is believed to encode long-term memories by altering synaptic connections between billions of neurones. There are trillions of such synapses in the cortex and its satellite organs. Memories are believed to be unstable and vulnerable to interference in the early hours after they are formed, and after about a day, they appear to be consolidated or made more enduring (Hobson \& Stickgold, 1995). This process of consolidation is thought to require protein synthesis and sleep and dreaming seem to support this process.

\subsection{Types of Learning}

Learning can be defined as the acquisition of lasting representations that involve a wide range of brain areas and activities (Baars \& Gage, 2010). Very often, the unstated goal of learning is to turn explicit problem solving into the implicit kind. Like we discussed explicit and implicit memories, learning can also be explicit or implicit. Explicit or declarative learning involves conscious learning while implicit (unconscious) learning (Berry \& Dienes, 1993; Cleeremans, 1993) results as a side effect of conscious input. That is, even for implicit learning, conscious events guide the learning process. But there is no exclusively conscious learning as both, conscious and unconscious processes always go together. In a complete learning cycle, three phases can be identified: learning, retention and retrieval. Retention is generally viewed as unconscious, although it is shaped by conscious experiences. Explicit learning generally occurs when we pay attention to new information so that it becomes conscious. The brain begins learning as soon as it is placed in any novel environment. Simple novelty is enough to trigger attention and learning, including significantly evoked potentials that sweep through the entire cortex. As soon as we experience or understand the new information with enough clarity, our brains can store it (Seitz \& Watanabe, 2005). Sometimes it may require repeated attention to new or difficult information for us to get a sense of clarity. Any new material may seem vague or hard to understand at first; however, when we spend time thinking about it or paying attention to it, a clearer sense of meaning tends to appear.

The most of our learning is identified to be incidental (Eide B. \& Eide F., 2004), meaning that it occurs because of paying attention and becoming conscious. That is, we do not deliberately memorise things all the time; memorising is only one way to make learning happen.

With our current practices, academic learning is mostly explicit with teachers pointing out the things to be learned and students doing their best to memorise them. However, most ordinary human learning is implicit 
(Bowers et al., 1990; James, 1890; Metcalfe, 1986; Yzerbyt et al., 1998). For example, social habits and language are mostly learnt implicitly. Looking from another perspective, the most of our knowledge is tacit knowledge, and the most of our learning takes place implicitly before it can be stated explicitly. Further, academic exams usually test associative recall (What is the capital of Australia?) rather than recognition tests. Associative recall tests give much lower estimates for accurate memories than recognition tests. That is, in the associative recall, we expect more exact and specific answers than in recognition tests. Interestingly, these exact and specific answers are the ones that are likely to be forgotten soon (Tulving, 1972, 1985).

In the event of some emotional stimuli, there is evidence that unconscious learning takes place. That is, this gives much stronger evidence for implicit learning, in which some inferential process takes conscious input and encodes unconscious results. In other words, emotional learning results in implicit emotional memory that retains classically conditioned emotional relationships that cannot be voluntarily recollected or reported (Phelps \& LeDoux, 2005; Panksepp, 1998). Psychological evidence shows that moderate levels of emotional arousal at the time of an event lead to better retention of explicit memories (Sylwester, 1998). That is, explicit memories are better consolidated by the reception of emotional stimuli by the amygdala.

\subsection{Consciousness}

Scientists have confirmed that consciousness can be defined and studied scientifically, contrary to the beliefs held otherwise, previously (Baars et al., 2003; Baars \& Gage, 2010; Edelman, 1989, 1993, 2005, 2007; Edelman \& Tononi, 2001; Koch, 1996; Palmer, 1999; Tononi \& Edelman, 1998; Tulving, 2002). Consciousness results from the neuronal interaction between thalamocortical systems; the neocortex is the main organ involved in it. The evolution of consciousness is understood to be the highest expression of the developed brain that parallels the evolution of the Pre-Frontal Cortex (PFC). Synonyms used for consciousness are awareness, explicit cognition and focal attention. Consciousness can be identified mainly in two levels-primary and higher-order consciousness. The former is concerned with the perceptual world while the latter is related to abstractions and thought. Further consciousness involves a range of contents: sensory perception, visual imagery, emotional feelings, inner speech, abstract concepts and action related ideas indicating the involvement of a number of brain regions, through an integrative view.

Of special interest to the phenomenon of consciousness is the theory developed by Giulio Tononi in the name of The Integrated Theory of Consciousness (Balduzzi \& Tononi, 2008; Koch \& Tononi, 2008; Tononi, 2008). It provides a new way to study consciousness using a rigorous scientific approach. The integrated theory of consciousness is a framework that is built on the notion that consciousness is a consequence of systems that have both a large amount of differentiated information that is also highly integrated. To summarise the idea, a computer may have a large quantity of memory (say $16 \mathrm{~GB}$ ), but since these memory pieces are not integrated, computers do not have consciousness. Scientists have also been able to quantify the level of consciousness with a measure called neural complexity (C) (Edelman \& Tononi, 2001). High values of C characterise conscious events and reflects the extent to which the dynamics of a neural system are both integrated and differentiated.

\subsection{Automaticity}

In general, the more predictable a sensorimotor skill becomes, the less of it will become conscious. The fading of conscious access to habitual skills is commonly called "automaticity" and it goes along with a loss of precise voluntary control over habitual details (Baars \& Gage, 2010; Chein \& Schneider, 2005; Coulthard et al., 2008; Langer \& Imber, 1979; Raaijmakers \& Shiffrin, 1992; Schneider, 2009; Shiffrin \& Schneider, 1977). Repetitive events tend to fade from consciousness unless they have special significance. That is, voluntary actions we are conscious with become automatic with practice. As they do so, we tend to lose executive control over them. In other words, effortful tasks show a wider spread of brain activity; the brain takes more time to solve novel problems and switching from one task to another seems to require additional mental resources beyond those involved in routine and automatic actions. The level of activity in the cortex (at least) drops with practice and automaticity. It seems to indicate the recruitment of neuronal resources that are needed to work together to perform a task that is new or unpredictable. 


\section{Introduction to Primarily Learning and Curriculum Design-Related Concepts That Can Be Viewed from Neuroscience}

\subsection{Transfer}

The phenomenon known as the transfer is one of the ultimate goals of teaching and learning. It encompasses the ability to learn in one situation and then use that learning, possibly in a modified or generalised form, in other situations (Sousa, 2011). The transfer is the key process involved in problem-solving, creative thinking, and all other higher mental processes of inventions and artistic products. Transfer can be described as a two-part process - transfer during learning and transfer of learning. In the former, the effects the past learning have on the acquisition and processing of new learning are highlighted, while in the latter, the degree to which the learner becomes capable of applying new learning to future situations is presented. Further, the transfer can be categorised as positive and negative transfers; in the positive transfer, past learning helps the learner with new learning, while past learning interferes with the learners understanding of new learning in the negative transfer. We can see here a close relationship between the concepts of making sense and meaning and transfer; the more the learner makes sense and meaning the better the function of transfer that takes place.

One way educators achieve successful transfer is by introducing integrated thematic units. Factors that affect the transfer process include the context and degree of original learning and critical attributes of a concept taught (Hunter, 2004). About the first factor, it is important to understand that if something is worth teaching, it needs to be taught well, while the second factor highlights the need to emphasise on unique characteristics of the concepts learned. Further, it is understood that significant and efficient transfer only occurs if we teach to achieve it (Hunter, 2004; Mestre, 2002; Perkins \& Saloman, 1988). The proper and frequent use of transfer greatly enhances the constructivist approach (Brooks \& Brooks, 1999) to learning, and vice versa.

\subsection{Sense and Meaning}

When the survival and emotional elements are not present, transferring information from short-term memory to long-term memory requires other factors that need to be addressed (Sousa, 2011). One such important factor is whether sense and meaning are attached to the new learning from the perspective of the learner. When the content or new learning makes sense to the learner, he/she can attach previous learning to the new learning. In other words, the learner can understand new learning based on what he/she knows about the world or how it operates. On the other hand, when meaning is attached to new learning, it is relevant to the learner, and there is a purpose or motivation for the learner to learn it. If both sense and meaning are present, the likelihood of transferring from the short-term to long-term storage is very high. Then it is understood to have substantially more cerebral activity followed by dramatically improved retention (Maquire, Frith, \& Morris, 1999; Poppenk, Kohler, \& Moscovitch, 2010; Rittle-Johnson \& Kmicikewycz, 2008). Of the two criteria, meaning has a greater impact on the probability that information will be stored in long-term memory. One way to attach meaning to new learning is helping students to make connections between subject areas by integrating curricular; it increases meaning and retention, especially when students recognise a future use of the new learning.

\subsection{Rehearsal}

Rehearsal is a critical component of learning that helps the transfer of information from working memory to long-term storage. There are two major factors associated with the process of rehearsal-the amount of time devoted to rehearsal and the type of rehearsal (Sousa, 2011). The amount of time devoted to rehearsal can be found in two stages, either initial or secondary rehearsal. Initial rehearsal occurs when information first enters working memory (when sense and meaning are attached). Several studies showed that during longer rehearsals, which may even take place at a secondary stage, the amount of activity in the frontal lobe determined whether items were stored or forgotten (Buckner, Kelley, \& Petersen, 1999; Wagner et al., 1998).

Another categorisation of the task of practising or rehearsal is whether it is massed practice or distributed practice. Practising new learning during time periods that are very close together is called massed practice; immediate memory is involved greatly here. Some example situations are mentally rehearsing a new phone number, cramming for an exam and trying a different example of applying new learning in a short period. In distributed practice, more sustained practice over time is done or introduce a spacing effect, which is the key to retention, as in the case of secondary rehearsal (Seabrook, Brown, \& Solity, 2005; Metcalfe, Kornell, \& Son, 2007; Carpenter, Pashler, \& Cepeda, 2009; Hunter, 2004). A spiral curriculum in which key concepts are revised at regular intervals is a method we can use to engage learners in distributed practice.

The type of rehearsal can also be either rote or elaborative rehearsal. When the learner has to remember information exactly the way it entered the working memory, it is termed as rote rehearsal. Some examples are 
when a poem, telephone number, or multiplication table is remembered. Elaborative rehearsal takes place when new learning is associated with prior learning to form new connections. The assignment of sense and meaning to new learning can only occur if the learner has adequate time to process and reprocess (rehearsal) it. When learners get very little time for elaborative rehearsal, they have no option but to resort more frequently to rote rehearsal.

\subsection{Chunking}

Chunking is a process in which working memory perceives or compresses a set of data as a single item as we perceive a set of letters as one word (Sousa, 2011). It appears to be an innate human characteristic related to our survival ability of seeking patterns in the environment (Feigenson \& Halberda, 2004; Brady, Konkle, \& Alvarez, 2009). Chunking occurs in 2 ways. In one situation, it is a deliberate and goal oriented process initiated by the learner such as learning a poem, increasing one line at a time. In other situations, it is more subtle, automatic and linked to perceptual processes as when we learn to read by increasing the number of words from a single word to two to a phrase and so on (Bor, Duncan, Wiseman, \& Owen, 2003). Since chunking allows us to deal with a few large blocks of information rather than a large number of small fragments, it gives us the ability to solve problems by accessing a large amount of relevant knowledge from long-term memory to be used in working memory. Further, chunking is more of an ability of organising our knowledge base for better use of limited working memory.

\subsection{Bloom's Taxonomy}

Blooms Taxonomy is one of the most popular models used for evaluating the level of learning for several years (Sousa, 2011). The original model of Bloom's Taxonomy (Bloom, Engelhart, Furst, Hill, \& Krathwohl, 1956) had six complexity levels, namely, Knowledge, Comprehension, Application, Analysis, Synthesis, and Evaluation. It held that the six levels were cumulative - a lower level needs to be satisfied before moving to a higher level. A revised model was presented in 2001 (Anderson et al., 2001) retaining all the six levels. In the revised taxonomy, names of all levels were changed to verb form, three levels renamed and two were interchanged to a classification of Remember, Understand, Apply, Analyse, Evaluate and Create. In contrast to the original model, the strict hierarchy in the 2001 revision has been loosened to allow levels to overlap one another.

\subsection{Inductive and Deductive Reasoning in Bloom's Taxonomy}

Recent neuroscience studies have found different cerebral regions were involved in solving problems of logic and sequence (deductive reasoning) than in solving open-ended problems with multiple answers (inductive reasoning) (Jausovec N. \& Jausovec K., 2000; Mihov, Denzler, \& Forster, 2010; Parsons \& Osherson, 2001). These evidence weaken Bloom's initial notion that one type of thinking is dependent on the prior activation of lower level thinking. Cognitive psychologists have observed that, more specifically, the thinking skills at the upper levels were a lot more fluid than Bloom's rigid hierarchy suggested.

\subsection{Convergent and Divergent Thinking in Bloom's Taxonomy}

Cognitive psychologists have generally divided thought into two categories: convergent, lower-order thinking and divergent, higher-order thinking. The lower three levels of Bloom's Taxonomy describe a convergent thinking process whereby the learner recalls and focuses what is known and comprehended to solve problems through the application. The upper three levels of the Taxonomy describe a divergent thinking process in which the learner come up with new insights and discoveries or relationships that were not part of the original information. Recent research studies show that elaborative rehearsal, involving higher-order thinking skills, engages the brain's frontal lobe. Further, they indicate that different parts of the brain are involved as more complex problem-solving tasks are handled (Cole, Bagic, Kass, \& Schneider, 2010; Kelly, Hester, Foxe, Shpaner, \& Garavan, 2006).

\subsection{The Constructivist Theory of Learning and Bloom's Taxonomy}

It is interesting to note that constructivist teachers, more specifically, ask open-ended questions and continually encourage students to analyse, evaluate and create (Brooks J. \& Brooks M., 1999). That is, it appears that teachers, who constantly use the upper levels of Bloom's revised taxonomy, are essentially demonstrating constructivist behaviours. However, we observe schooling still demands mostly the processing levels of convergent thinking. Common pedagogical practices and assessment focus on content acquisition through rote rehearsal, rather than on processes of analysis, synthesis and evaluation. Repeating the exact answers becomes more important than the processes used to get the answer. 


\subsection{Bloom's Taxonomy and Complexity and Difficulty Levels}

About Bloom's Taxonomy, the terms complexity and difficulty are used to describe different mental operations. However, often we find them being used synonymously. In Boom's Taxonomy, we say, there are six levels of complexity. Complexity describes the thought process or a level of thought that the brain uses to deal with information. The difficulty, on the other hand, refers the amount of effort, and possibly time, that the learner must expend, usually within a single level of complexity, while engaging in learning. It is worth realising that a certain learning activity can become increasingly difficult without becoming more complex.

\subsection{Application of Bloom's Taxonomy for Achieving Higher-Order Learning}

It has been observed that if teachers understand and follow the revised Bloom's Taxonomy correctly, all members of a learner cohort, irrespective of individual differences, can be sent through a process of higher-order learning. One way to make this practically possible is to review the curriculum and remove the topics of the least importance to gain the time needed for practising at higher levels. Another approach is to integrate the new concepts with previously taught material and connect them to appropriate concepts in the other curriculum areas; here we are essentially using the process of transfer more appropriately in the teaching-learning context.

\subsection{Types of Problem Solving/Decision Making}

Individuals need to become better decision makers and problem solvers through education. In schools or colleges, we are usually given a problem or question, and we must find or write the correct answer (Baars \& Gage, 2010). Usually, only one correct answer exists to these questions or problems. For example, balancing a chequebook and remembering the capital city of a country are similar tasks. By finding the correct solution, we engage in veridical decision-making. However, apart from high school exams, college tests and factual and computational trivia, most decisions we make in our everyday lives do not have intrinsically correct solutions. That is, the decisions we make are not always objective, rather they are, in most cases, subjective. What career path to make, what location to visit on vacation are some such example decisions we make in ambiguous situations. By making a decision or choice, we engage in adaptive decision-making. Further, our best neural system performance is not for the exact symbol sequences that conventional computers handle so well. Rather, our brains are exceptionally good at dealing with complex, ill-defined, and novel challenges, the kinds that people must deal with in the real world. That is, humans are exceptionally flexible in adapting to new conditions.

The choices we make are not inherent in the situations at hand. There is a complex interplay between the properties of the situations and our individual properties, aspirations, doubts, and histories. The Pre-Frontal Cortex (PFC) is central to such decision-making or evaluation. Finding solutions for deterministic situations often is accomplished algorithmically or following several steps routinely. These tasks are increasingly delegated to various devices such as calculators, computers and the like. However, making judgments, in the absence of inherently correct solutions, remain, at least for now, a uniquely human territory. Thus, through education, an individual must develop the capacity to have the flexibility to adopt different perspectives on the same situation at different times. The organism must be able to disambiguate the same situation in multiple different ways and to have the capacity to switch between them at will. Frontal lobes of the brain hemispheres play an important role in dealing with these ambiguous situations.

\section{Curriculum Construction Following the Concepts from Educational Neuroscience}

\subsection{Expectations of a Curriculum Based on the Inputs from Educational Neuroscience}

When a well designed and constructed curriculum is implemented within a stipulated period, we expect that the learners retain lasting new memories or neural connections of knowledge that will be useful in numerous ways. Ideally, these memories or connections they would make should not confine to a single area of study, disciplinary area or profession; instead, learners should be able to use the memories retained or connections identified more broadly in any appropriate real-life situation. If this is achieved, we say that transfer of learning has taken place and learners are en route to develop enhanced wisdom (Claxton, 2008; Watagodakumbura, 2016) or consciousness (Watagodakumbura, 2015a, 215b). When enhancing wisdom or consciousness is the focus, we make many regions of the brain to function holistically in an integrated manner leading to higher levels of human development (Maslow, 1968, 1993; Dabrowski, 1970, 1972, 1977; Watagodakumbura, 2016). The area of study, in effect, becomes only an application or the medium through which some useful real-life phenomena or concepts are introduced and learnt. Here, we deemphasise on the particular area or field of study, and instead, highlight high-level more generalised concepts or knowledge. From the findings of neuroscience, we know that high-level or more generalised knowledge/concepts are retained as lasting semantic memories, as opposed to episodic memories. Consequently, it is important that we highlight generalised high-level concepts throughout 
our curriculum. By doing this, we enable transfer of knowledge as if protruding neural sensors of learners are waiting to be connected to any related piece of knowledge or application. The outcome of the curriculum is not an end itself, but a means by which the learners can make more connections or neural networks of knowledge in future as they get exposed to further knowledge and experiences in a lifelong journey (Watagodakumbura, 2015c, 2015d). A broadly-based curriculum like this will attract learners' motivation better, as it is useful in a more generic sense. It is not because of opening-up of a specific career-path, the prospects of which might change significantly over a relatively small period, that learners are motivated, but because of the opportunity that opens for becoming better decision makers as a whole or in human development as a self-actualising (Maslow, 1968, 1993) and creative human being with a higher-level of consciousness and/or wisdom. In other words, the result of carrying out a curriculum does not mean that learners got introduced to some new contents, and they could overcome the end-of-curriculum assessment barriers (sometimes set with a lower-order focus or rote learning focus) successfully, without necessarily retaining useful high-level concepts of memories in a lasting manner. Such a curriculum will lack the essential characteristics of validity and having lasting outcomes (or transfer of learning). Engagement in the curriculum at a higher level of motivation or with some emotional attachment is the key to achieving enhanced learning, the essential means of reaching a higher level of human development (Dabrowski, 1970, 1972, 1977).

From another perspective, curricula we design must send learners essentially on a path to higher-order learning or divergent and inductive thinking processes. That is, the curricula direct towards the high-end of Bloom's Taxonomy - the levels of evaluation and creation. In effect, learners are given a conducive environment to develop new insights by connecting various neural networks of knowledge appropriately and evaluate then against each other. They are essentially making use of the frontal lobes, the organ of civilisation, for integration of knowledge networks. Then, the learners will yield a lasting value from the curricula with proper transfer of learning. Such curricular can be contrasted with the ones that focus on the short-term and narrow development of skills, which may be rendered useless in the near future in a rapidly changing world. Further, on a related matter, we accommodate the use of learners' right cerebral hemispheric characteristics such as creativity and visual-spatial abilities (Silverman, 1998, 2002) as opposed to focusing merely on left cerebral hemispheric features such as auditory sequential skills. Consequently, widely discussed disadvantageous situations faced by visual-spatial or gifted learners (Silverman, 1998, 2002; Webb, 2005, 2008; Watagodakumbura, 2016) are minimised, producing a fairer educational environment overall in a neurodiverse society (Armstrong, 2011; Watagodakumbura, 2016).

\subsection{Deciding on the Content to Be Introduced in a Curriculum}

As curriculum designers and constructors, how should we decide on what contents to be included? What are the design parameters we take into consideration? In most cases of curriculum development, we should be able to find a standard textbook in the area under consideration. In fact, it is a good idea if we can stick to one selected textbook as it provides learners with a clearer direction on the scope of the contents and curriculum and the convenience of not having to jump among different sources. Especially, if the curriculum in focus is in a fundamental knowledge area that has been well established, we are in a better position to select a single textbook that serves our purpose of introducing the fundamental knowledge. By doing this, we will save a lot of time for our learners for an elaborative rehearsal of concepts rather than spend time for identifying useful sources of content. If the area of the curriculum we construct is not a well established one or still evolving through ongoing research, we should make useful reading references available for the learners. Since the aim of a curriculum is to create lasting memories or neural connections of knowledge for further connectivity in future, we should save learners time for elaborative rehearsals, which is the basis for forming useful knowledge networks.

\subsection{Becoming Conscious of the Limited Time Available for Carrying out a Curriculum and the Need to Adjust the Contents Accordingly}

An important parameter curriculum constructors need to be conscious of when deciding the contents to be included in a curriculum is the fact that time available for carrying out the curriculum satisfactorily (without rushing) is limited. Thus, we may not be able to discuss all the sub sections in the curriculum area in detail or all the chapters of the selected text book. We emphasise here that in-depth delving of the significant knowledge areas we selected and introduce is more important than extending to less significant sub areas of content in a matter of urgency. Essentially, we must prioritise the high-level concepts we are going to highlight and include them in the curriculum for discussion, starting from the top of the list and covering as many as time permits. We should never be carried away by the notion that learners only learn what is presented in a classroom environment and as a consequent, as many important concepts/sections as possible need to packed tightly into a curriculum 
(Watagodakumbura, 2015d). It is worth paying attention to the fact that most of our learning is implicit, that is not done in a classroom environment. In this era of information and communication technologies in which relevant information is easily searchable and received onto one's table, what is important is to introduce learners to the fundamental knowledge of the curriculum area deeply to raise his/her curiosity and motivation levels for furthering this knowledge when required. In effect, what we should cover in a curriculum is the most important high-level or generalised concepts that can be comfortably elaborated within the available limited time with enough emphasis. To highlight high-level generalised knowledge, which is stored as lasting semantic memories, we may have to cut down on and lessen emphasis on more specific details or narrower knowledge. A curriculum is not an end to learning itself in the area of focus; rather it is the means by which an interest in the learners is raised for them with open minds to further their knowledge or neural networks en route to a higher level of human development (Maslow, 1968, 1993; Dabrowski, 1970, 1972, 1977; Watagodakumbura, 2016). Consequently, at the end of the implementation of the curriculum at the end of the stipulated time, the learners must be left with positive reminiscences. The implications of negative reminiscences can have severe detrimental impact on learners' human development; they may create permanent barriers on extending learning, especially in the area of focus, albeit quite unrealistically in most cases. For example, a learner who is capable of learning abstract theories well may not receive a curriculum well as it paid emphasis on a large number of more specific details as opposed to on high level generalised concepts. The result may be developing a negative attitude towards the area of study by the learner inadvertently, when the real issue was with the focus or content of the curriculum, despite the learner possessing a highly useful ability of learning abstract theories.

\subsection{Deciding and Designing the Learning Material/Documents That Are Made Available to Learners}

In addition to prescribing an appropriate textbook for the curriculum we carry out, we can make summaries of important high-level concepts available to learners for their reference. A learner new to the area of study would find reading the detailed descriptions of a typical textbook useful. However, the learner will benefit from a summary highlighting the important high-level concepts as a second-time reading that can be carried out relatively quickly. When reading a detailed textbook, it is possible that learners get lost in details, de-emphasising the importance of high-level concepts learned. Even though detailed descriptions would help "understanding" as the term is used in the Bloom's taxonomy or making sense, they may not help learners to make meaning or lasting memories in the form of semantic memories, the residual that would be useful in the longer run. The latter task of making meaning or helping to create semantic memories can be supported by providing a high-level summary of the important concepts. From another point of view, our working memory has a limited capacity, and when it is filled with specific details, as in the case of reading the book, instead of high-level concepts, we may not be able to relate what we learn to our existing knowledge (make sense) efficiently. The reason for this is that it is easier make connections with the high level the concepts than with specific details, as highlighted before (Watagodakumbura, 2015a, 2015d). Consequently, when we go through the high-level concepts only, using the provided summary of concepts that exclude specific details, in a second reading, we can fill our limited capacity working memory with as many high-level concepts as it permits and makes connections with existing knowledge networks better or more efficiently. Also, human brain's inclination or capacity of chunking information together is supported when high-level or abstract concepts are highlighted.

\subsection{Presenting Summaries of Contents or High-Level Concepts Appropriately in the Learning Support Documents Provided (Instructional Design Based on Educational Neuroscience)}

Another important decision we should make is how we are going to present the important high-level concepts to learners within the documents or learning aids provided. In other words, what instructional design strategies can we follow for effective learner engagement. We need to compile these documents in a manner that they can be used as a standalone resource at least for a familiar reader. In other words, we should avoid point-form partial sentences as they lack in information that can be connected to the context readily; instead, we should highlight concepts using more contextual complete sentences that help to provide meaning in a continuum. Providing complete contextual sentences instead of isolated pieces of information will help learners to make connections among pieces of knowledge or neural networks, even when going through the content after a lapse of a long period. Isolated pieces of information will only push learners on a strategic learning path of merely obtaining a higher grade (if assessments allow that by nature) by encouraging them to get these disconnected pieces of information into short-term memory through rote rehearsal. Further, additional specific details we may include for the sake of providing more context or clarity can be provided with indentation on a sub level so that readers identify optional or additional reading content depending on their familiarity with the content area. 


\subsection{Deciding and Designing Assessment Components of a Curriculum}

In a curriculum design process, one of the most important tasks is preparing appropriate assessment components (Watagodakumbura, 2015b, 2015d). Learners, in general, associate with a curriculum from the perspective of assessment tasks used. Consequently, assessments should be constructed to guide learners on short or mid-term objectives aligned towards long-term or lifelong learning goals. When learners fulfil objectives of these assessments, ideally, they should be on a path to achieving long-term goals of enhancing consciousness or wisdom (Claxton, 2008; Watagodakumbura, 2016). A curriculum or associated assessments should not be an end itself, after carrying out the curriculum, completing the assessment and awarding grades and simply move onto a new curriculum without retaining any lasting value from the completed curriculum. The assessment we set within a curriculum should direct learners on a path to higher-order learning. They must be encouraged to identify new connections among the existing neural networks of knowledge and newly introduced ones in an idiosyncratic or creative manner by making sense and meaning. As opposed to being passively retrieving information from sources, learners should be fostered and encouraged to engage actively in the process of creating inferences in a sensible manner or within an existing framework of knowledge.

There are many different types of assessment used by educational practitioners for evaluating learners. To decide what types of assessment we can use within our curriculum, first, we should understand the intended purpose of our assessment clearly. Ideally, the evaluation should provide an indication how well a learner has formed lasting memories or neural networks of knowledge that lead to a higher level of human development. In other words, we assess how well the transfer of knowledge or higher order learning has taken place within the learners. For example, using Bloom's taxonomy, we can assess how well learners can perform evaluation and creation tasks that involve divergent thinking or inductive learning. To achieve these objectives, we can use open-ended, novel and conceptual questions assessing the abilities for adaptive decision making as opposed to assessing abilities for veridical decision making. These high-level conceptual questions will test the learners' abilities to recall lasting memories stored as long-term semantic memory spontaneously. What we should deviate from is assessing how well a learner has committed facts or specific details in their original form presented into short term memory, mostly just before the assessment. Such assessments are said to have a focus on what is referred to as rote learning, encouraging learners to engage in rote rehearsal that has little value in making positive attitudinal and behavioural changes within learners.

In addition to deciding the types of assessments used as above, we should decide on how many assessments we may use during the stipulated time in which the curriculum is implemented. Too many assessments will distract the learners from the main purpose of the curriculum - learning or creating lasting memories or neural networks of knowledge; the focus will be more onto the rituals or overheads of attending and completing the assessments. When carrying out the curriculum, we need to develop a culture within the classroom or teaching-leaning environment to intrinsically motivate the learners for learning, rather than introducing assessment items for them to get to learn. If assessments are not properly set up to evaluate higher-order learning, and learners are extrinsically motivated to obtain a higher grade from such an assessment, learners will achieve little from their efforts regarding human development into creative human beings is concerned. They are not likely to create lasting semantic memories or neural networks of knowledge that will be useful in many or generic ways. Consequently, a minimal number of properly constructed assessments as appropriate will put learners on the right track towards achieving higher-order learning.

Another important decision we must make is the coverage of the assessment. Ideally, assessments should cover all the areas highlighted within the curriculum proportionately to the time spent in each area. It is not to say that we must ask every possible question within each section covered in the curriculum; rather it is a statistical analysis in which a sample set of questions across the whole curriculum is selected to make some valid and useful inferences on student learning. By limiting the size of the set of questions we select for an assessment, we provide learners a longer time to provide more contemplative and creative answers to the selected questions utilising the frontal lobes of the brain, instead of encouraging learners to provide premeditated or previously practised answers rapidly. This time factor consideration is more specifically applicable to timed assessments. Also, when we cover the all sections of the curriculum in assessments, we discourage learners from following a strategic path to higher grades by selecting only some sections from the curriculum to engage in elaborate rehearsal or deep learning. 


\subsection{Deciding on How to Balance Theory and Practical Components (If Applicable)}

Some units or courses we teach or set curricular have essential practical components as part of learning. In general, courses related to science and technology will have practical components as part of the curriculum. For these units or courses, we must carefully decide on the specific practical components to be incorporated, and the amount of time we expect to expend on them (Watagodakumbura, 2016). The intention of introducing a practical component is to get the learners exposed to relevant real-life experiences or applications. Exposure to these applications or experiences will enable learners to understand or generalise underlying abstract theories or concepts better. While some learners, especially the right hemispheric oriented ones, learn abstract concepts more easily, others with a left hemispheric orientation will benefit from practical exposure to enhance understanding of abstract theories. We make a clear distinction here that our intention is not to make learners highly skilled in the respective practical component; such skills must be developed over time through continuous practice of some purpose. As we highlighted before, when we engage in a specific activity for a reasonably longer period, our brains get used to performing them automatically utilising relatively less neocortical resources. We referred to this phenomenon as automaticity. Such a high skill level can be achieved if a learner is interested and motivated in the activity in the longer run, but our intention is not to make learners master a certain skill within the limited time available for implementing the curriculum. Consequently, it is better to limit the time spent on practical components appropriately, especially if it does not help learners to develop lasting memories or neural networks of knowledge. In other words, just because we can find a tool or device conveniently for learners to get involved, we should not get them to spend the limited curriculum time on extensively using or mastering these tools or devices for no added and lasting value of learning. When human development into creative human beings is the goal of learning, the emphasis in any teaching-learning environment must be on high-level generalised concepts while essential practical exposure can be used to enhance the digestion of these concepts. To reiterate, if a course or unit is mostly aimed at developing a certain motor skill in the learners, it will not have the real learning value per se that will retain lasting semantic memories.

\subsection{Additional Considerations or Suggestions for Curriculum Design and Construction}

Within a curriculum, it is advisable that we promote learner independence and discovery that prepare learners for the journey of lifelong learning. To achieve, this we may introduce a topic area briefly for learners so that they can perform a task of discovery learning, taking an active initiative. Learners can be motivated to pursue this activity by allocating $10 \%-15 \%$ (as a general guide) of assessment marks for satisfactorily engaging is this discovery learning process. With this approach, we can pass the important message of learner initiative required in learning. Further, we get an opportunity to evaluate the most common form of human learning-implicit or incidental learning. It would also motivate gifted learners, who are more inclined to learn implicitly or incidentally, to better engage in such a curriculum than a traditional one. We should be mindful that we can increase the percentage of discovery learning within a curriculum as appropriate, even to $100 \%$ depending on the learning environment or learner cohort.

\section{Conclusion}

It is the time that educators embrace the knowledge emerging from the field of educational neuroscience for accomplishing enhanced learning. In this article, we have more specifically discussed principles and notions of educational neuroscience that guide us in curriculum design and construction. First and foremost, the purpose of a curriculum is understood essentially to be supporting human development to higher levels or self-actualisation in a lifelong process. Such a curriculum will guide learners to enhance wisdom and consciousness, phenomena that make use of the frontal lobes of the brain to integrate neural networks of knowledge across multiple brain regions. Contents that go into a curriculum, which has a limited time to carry out, is an important design parameter. The most important abstract concepts can be selected from a prioritised list, as they are stored as semantic memories in a lasting manner, and following the principle of chunking, they contain a large volume of information in a concise manner. In the study-aid documents provided to learners, we can arrange the contents in a hierarchical manner (as an inverted tree), most abstract concepts at the top or the root and more specific details at the bottom or on leaves. Such an organisation of information helps learners to go through the most important concepts relatively quickly and more efficiently, and browse through the details only if necessary or more clarifications are needed. As a part of the curriculum design and construction process, forming assessment appropriately needs to be diligently handled. These assessments are required to essentially test the level of learners' engagement in higher-order learning, divergent thinking or inductive processing. These are the levels described at the high-end of Bloom's Taxonomy. For this purpose, we can make use of open-ended conceptual questions accommodating learners to provide subjective, individualised or creative responses within a valid 
framework. Consequently, we get an opportunity to conduct fairer assessment enabling us to evaluate most prevalent implicit or incidental learning components as well. In some curricula, in the areas such as science and technology education, we can include practical components appropriately and with careful thought making sure that the time expended on them help learners to understand abstract theories better or provides an added value towards enhanced learning. Finally, as an additional consideration in the task of curriculum design and construction, we presented having a discovery learning exercise leading to learner independence that would guide and train learners in the process of lifelong learning.

\section{References}

Airasian, P. W., Cruikshank, K. A., Mayer, R. E., Pintrich, P. R., Raths, J., \& Wittrock, M. C. (2001). A taxonomy for learning, teaching and assessing: A revision of Bloom's Taxonomy of Educational Objectives (L. W. Anderson \& D. R. Krathwhol, Eds., Complete edition). New York: Longman.

Armstrong, T. (2011). The Power of Neurodiversity: Unleashing the Advantages of Your Differently Wired Brain. Da Capo Lifelong Books.

Baars, B. J., \& Gage, N. M. (2010). Cognition, Brain, and Consciousness-Introduction to Cognitive Neuroscience (2nd ed.). Elsevier, MA: USA.

Baars, B. J., Banks, W. P., \& Newman, J. B. (2003). Essential sources in the scientific study of consciousness. Cambridge: MIT Press.

Baddeley, A. D. (2000). The episodic buffer: A new component of working memory? Trends in Cognitive Sciences, 4(11), 417-423. https://doi.org/10.1016/S1364-6613(00)01538-2

Baddeley, A. D., \& Hitch, G. J. (1974). Working memory. In G. A. Bower (Ed.), Recent advances in learning and motivation: 8 (pp. 47-90). New York: Academic Press. https://doi.org/10.1016/s0079-7421(08)60452-1

Balduzzi, D., \& Tononi, G. (2008). Integrated Information in Discrete Dynamical Systems: Motivation and Theoretical Framework. PLoS Computational Biology, 4(6). https://doi.org/10.1371/journal.pcbi.1000091

Banaji, M. R., \& Greenwald, A. G. (1995). Implicit gender stereo-typing in judgements of fame. Journal of Personality and Social Psychology, 68(2), 181-198. https://doi.org/10.1037/0022-3514.68.2.181

Berry, D. C., \& Dienes, Z. (1993). Implicit learning: Theoretical and empirical issues. Erlbaum.

Bor, D., Duncan, J., Wiseman, R. J., \& Owen, A. M. (2003). Encoding strategies dissociate prefrontal activity from working memory demand. Neuron, 37, 361-367. https://doi.org/10.1016/S0896-6273(02)01171-6

Bowers, K. S., Regehr, G., Balthazard, C., \& Parker, K. (1990). Intuition in the context of discovery. Cognitive Psychology, 22(1), 72-110. https://doi.org/10.1016/0010-0285(90)90004-N

Brady, T. F., Konkle, T., \& Alvarez, G. A. (2009). Compression in visual working memory: Using statistical regularities to form more efficient memory representations. Journal of Experimental Psychology, 138, 487-502. https://doi.org/10.1037/a0016797

Brooks, J. G., \& Brooks, M. G. (1999). In search of understanding: The case for constructivist classrooms (2nd ed.). Alexandria, VA: Association for Supervision and Curriculum Development.

Buckner, R. L., Kelley, W. M., \& Petersen, S. E. (1999). Frontal cortex contribution to human memory formation. Nature Neuroscience, 2, 311-314. https://doi.org/10.1038/7221

Carpenter, S. K., Pashler, H., \& Cepeda, N, J. (2009). Using tests to enhance $8^{\text {th }}$ grade students' retention of U.S. history facts. Applied Cognitive Psychology, 23, 760-771. https://doi.org/10.1002/acp.1507

Chein, J. M., \& Schneider, W. (2005). Neuroimaging studies of practice-related change: FMRI and meta-analytic evidence of a domain-general control network for learning. Brain Research. Cognitive Brain Research, 25(3), 607-623. https://doi.org/10.1016/j.cogbrainres.2005.08.013

Claxton, G. (2008). Wisdom: Advanced Creativity? In A. Craft, H. Gardner, \& G. Claxton (Eds.), Creativity, Wisdom and Trusteeship: Exploring the Role of Education. Thousand Oaks, CA: Corwin Press.

Cleeremans, A. (1993). Mechanisms of implicit learning: Connectionist models of sequence learning. MIT Press.

Cohen, N. J., \& Squire, L. R. (1980). Preserved learning and retention of pattern-analysing skill in amnesia: Dissociation of knowing how and knowing that. Science, 210(4466), 207-210. https://doi.org/10.1126/science.7414331 
Cole, M. W., Bagic, A., Kass, R., \& Schneider, W. (2010). Prefrontal dynamics underlying rapid instructed task learning reverse with practice. The Journal of Neuroscience, 30(42), 14245-14254. https://doi.org/10.1523/JNEUROSCI.1662-10.2010

Coulthard, E. J., Nachev, P., \& Husain, M. (2008). Control over conflict during movement preparation: Role of posterior parietal cortex. Neuron, 58(1), 144-157. https://doi.org/10.1016/j.neuron.2008.02.009

Cowan, N., Izawa, C., \& Ohta, N. (2005). Working-memory capacity limits in a theoretical context. Human learning and memory: Advances in theory and application. In The $4^{\text {th }} T$ sukuba International Conference on Memory (p. 155). Mahwah: Lawrence Erlbaum Associates, Publishers. https://doi.org/10.4324/9780203342398

Curran, T. (2001). Implicit learning revealed by the method of opposition. Trends in Cognitive Sciences, 5(12), 503-504. https://doi.org/10.1016/S1364-6613(00)01791-5

Dabrowski, K. (1970). Mental Growth through Positive Disintegration. London: Gryf Publications.

Dabrowski, K. (1972). Psychoneuroses Is Not An Illness. London: Gryf Publications.

Dabrowski, K. (1977). Theory of Levels of Emotional Development (Vol 1)-Multilevelness and Positive Disintegration. New York: Dabor Science Publications.

Dudai, Y. (2004). The neurobiology of consolidations, or how stable is the engram? Annual Review of Psychology, 55, 51-86. https://doi.org/10.1146/annurev.psych.55.090902.142050

Edelman, G. M. (1989). The remembered present: A biological theory of consciousness. New York: Basic Books Inc.

Edelman, G. M. (1993). Neural Darwinism: Selection and re-entrant signalling in higher brain function. Neuron, 10(2), 115-125. https://doi.org/10.1016/0896-6273(93)90304-A

Edelman, G. M. (2005). Wider than the Sky: The Phenomenal Gift of Consciousness. Yale University Press, New Haven.

Edelman, G. M. (2007). Second Nature: Brain Science and Human Knowledge. Yale University Press, New Haven.

Edelman, G. M., \& Mountcastle, V. B. (1978). The mindful brain: Cortical organisation and the group-selective theory of higher brain function. Oxford: MIT Press.

Edelman, G. M., \& Tononi, G. (2001). A universe of consciousness: How matter becomes imagination. New York: Basic Books Inc.

Eide, B., \& Eide, F. (2004). Brains on Fire: The Multimodality of Gifted Thinkers. New Horizons for Learning. School of Education, Johns Hopkins University. Retrieved from http://education.jhu.edu/PD/newhorizons/Neurosciences/articles/

Engelhart, M. D., Furst, E. J., Hill, W. H., \& Krathwohl, D. R. (1956). Taxonomy of educational objectives: The classification of educational goals. Handbook 1: Cognitive domain (Bloom, B. S., Ed.). New York: David McKay.

Feigenson, L., \& Halberda, J. (2004). Infants chunk object arrays into sets of individuals. Cognition, 91, 173-190. https://doi.org/10.1016/j.cognition.2003.09.003

Fuster, J. M. (1997). Network memory. Trends in Neurosciences, 20(10), 451-459. https://doi.org/10.1016/S0166-2236(97)01128-4

Gazzaniga, M. S. (1998a). The mind's past. Berkeley: University of California Press.

Gazzaniga, M. S. (1998b). The split brain revisited. Scientific American, 279, 48-55. https://doi.org/10.1038/scientificamerican0798-50

Gazzaniga, M. S., Ivry, R. B., \& Mangun, G. R. (2002). Cognitive neuroscience: The biology of the mind (2nd ed.). New York: Norton.

Geschwind, N. (1979). Specialisations of the human brain. Scientific American, 241(3), 180-199. https://doi.org/10.1038/scientificamerican0979-180

Goldberg, E. (2001). The executive brain: Frontal lobes and the civilised mind (Vol. xix). New York: Oxford University Press. 
Hobson, J. A., \& Stickgold, R. (1995). Sleep. Sleep the beloved teacher? Current Biology, 5(1), 35-36. https://doi.org/10.1016/S0960-9822(95)00011-X

Hunter, M. (2004). Mastery Teaching. Thousand Oaks, CA: Corwin.

Ingvar, D. H. (1985). Memory of the future: An essay on the temporal organisation of conscious awareness. Human Neurobiology, 4(3), 127-136.

James, W. (1890). The principles of psychology (Vol. I). New York: Henry Holt and Co, Inc. https://doi.org/10.1037/11059-000

Jausovec, N., \& Jausovec, K. (2000). EEG activity during the performance of complex mental problems. International Journal of Psychophysiology, 36, 73-88. https://doi.org/10.1016/S0167-8760(99)00113-0

Kelly, A. M. C., Hester, R., Foxe, J. J., Shpaner, M., \& Garavan, H. (2006). Flexible cognitive control: Effects of individual differences and brief practice on a complex cognitive task. Neuroimage, 31, 866-886. https://doi.org/10.1016/j.neuroimage.2006.01.008

Knowlton, B. J., Mangels, J. A., \& Squire, L. R. (1996). A neostriatal habit learning system in humans. Science, 273(5280), 1399-1402. https://doi.org/10.1126/science.273.5280.1399

Koch, C. (1996). A neural correlates of consciousness? Current Biology, 6(5), 492. https://doi.org/10.1016/S0960-9822(02)00519-5

Koch, C., \& Tononi, G. (2008). Can Machines be Conscious? IEEE Spectrum, 45(6), 55-59. https://doi.org/10.1109/MSPEC.2008.4531463

Langer, E. J., \& Imber, L. G. (1979). When practice makes imperfect: Debilitating effects of overlearning. Journal of Personality and Social Psychology, 37(11), 2014-2024. https://doi.org/10.1037/0022-3514.37.11.2014

LeDoux, J. E. (1996). The emotional brain. New York: Simon \& Schuster.

Lees, G. V., Jones, E. G., \& Kandel, E. R. (2000). Expressive genes record memories. Neurobiology of Disease, 7(5), 533-536. https://doi.org/10.1006/nbdi.2000.0348

Luria, A. R. (1966). Higher cortical functions in man (Haigh, trans.). London: Tavistock.

Luria, A. R. (1976). The neuropsychology of memory (Haigh, trans.). Oxford: V. H. Winston \& Sons.

MacLean, P. D. (1967). The brain in relation to empathy and medical education. The Journal of Nervous and Mental Disease, 144(5), 374-382. https://doi.org/10.1097/00005053-196705000-00005

Maquire, E. A., Frith, C. D., \& Morris, R. G. M. (1999). The functional neuroanatomy of comprehension and memory: The importance of prior knowledge. Brain, 122, 1839-1850. https://doi.org/10.1093/brain/122.10.1839

Maslow, A. (1968). Toward a Psychology of Being. New York: Van Nostrand Reinhold.

Maslow, A. (1993). Farther Reaches of Human Nature. New York, N.Y., U.S.A.: Arkana.

McGaugh, J. L. (2000). Memory-A century of consolidation. Science, 287(5451), 248-251. https://doi.org/10.1126/science.287.5451.248

Mestre, J. (2002). Transfer of learning: Issues and research agenda. Arlington, VA: National Science Foundation.

Metcalfe, J. (1986). Feeling of knowing in memory and problem solving. Journal of Experimental Psychology. Learning, Memory, and Cognition, 12(2), 288-294. https://doi.org/10.1037/0278-7393.12.2.288

Metcalfe, J., Kornell, N., \& Son, L. K. (2007). A cognitive-science based programme to study efficacy in a high and low-risk setting. European Journal of Cognitive Psychology, 19, 743-768. https://doi.org/10.1080/09541440701326063

Mihov, K. M., Denzler, M., \& Forster, J. (2010). Hemispheric specialisation and creative thinking: A meta analytic review of lateralisation of creativity. Brain and Cognition, 72(3), 442-448. https://doi.org/10.1016/j.bandc.2009.12.007

Nauta, W. J. (1972). Neural association of the frontal cortex. Acta Neurobiologiae Experimentalis (Wars), 32(2), 125-140. 
Palmer, S. E. (1999). Colour, consciousness, and isomorphism constraint. Discussion 944-989. The Behavioural and Brain Sciences, 22(6), 923-943. https://doi.org/10.1017/S0140525X99002216

Panksepp, J. (1998). Affective neuroscience: The foundations of human and animal emotions. New York: Oxford University Press.

Parsons, L. M., \& Osherson, D. (2001). New evidence for distinct right and left brain systems for deductive versus probabilistic reasoning. Cerebral Cortex, 11, 954-965. https://doi.org/10.1093/cercor/11.10.954

Penfield, W., \& Milner, B. (1958). Memory deficit produced by bilateral lesions in the hippocampal zone. AMA $\begin{array}{llll}\text { Archives of Neurology and } & \text { Psychiatry, } & \text { 79(5), }\end{array}$ https://doi.org/10.1001/archneurpsyc.1958.02340050003001

Perkins, D., \& Salomon, G. (1988). Teaching for Transfer. Educational Leadership, 46, 22-32.

Phelps, E. A., \& LeDoux, J. E. (2005). Contributions of the amygdale to emotion processing: From animal models to human behaviour. Neuron, 48(2), 175-187. https://doi.org/10.1016/j.neuron.2005.09.025

Poppenk, J., Kohler, S., \& Moscovitch, M. (2010). Revisiting the novelty effect: When familiarity, not novelty, enhances memory. Journal of Experimental Psychology: Learning, Memory and Cognition, 36, 1321-1330. https://doi.org/10.1037/a0019900

Raaijmakers, J. G., \& Shiffrin, R. M. (1992). Models for recall and recognition. Annual Review of Psychology, 43, 205-234. https://doi.org/10.1146/annurev.ps.43.020192.001225

Rittle-Johnson, B., \& Kmicikewycz, A. O. (2008). When generating answers benefits arithmetic skill: The importance of prior knowledge. Journal of Experimental Child Psychology, 101, 75-81. https://doi.org/10.1016/j.jecp.2008.03.001

Ryle, G. (1949). The concept of mind. London: Hutchinson.

Schneider, W. (2009). Automaticity and consciousness. Elsevier Encyclopaedia of Consciousness. In W. Banks (Ed.), Encyclopaedia of Consciousness (1st ed., pp. 83-92). Amsterdam: Academic Press. https://doi.org/10.1016/B978-012373873-8.00009-8

Seabrook, R., Brown, G. D. A., \& Solity, J. E. (2005). Distributed and massed practice: From laboratory to classroom. Applied Cognitive Psychology, 19, 107-122. https://doi.org/10.1002/acp.1066

Seitz, A., \& Watanabe, T. (2005). A unified model for perceptual learning. Trends in Cognitive Science, 9(7), 329-334. https://doi.org/10.1016/j.tics.2005.05.010

Semenza, C., Delazer, M., Bertella, L., Grana, A., Mori, I., Conti, F. M., ... Mauro, A. (2006). Is math lateralised on the same side as language? Right hemisphere aphasia and mathematical abilities. Neuroscience Letters, 406, 285-288. https://doi.org/10.1016/j.neulet.2006.07.063

Shiffrin, R. M., \& Schneider, W. (1977). Controlled and automatic human information processing: II. Perceptual learning, automatic attending and a general theory. Psychological Review, 84(2), 127. https://doi.org/10.1037/0033-295X.84.2.127

Silverman, L. K. (1998). Personality and Learning Styles of Gifted Children. In Excellence in Educating Gifted \& Talented Learners (3rd ed.). USA: Love Publishing Company.

Silverman, L. K. (2002). Upside-Down Brilliance: The Visual-Spatial Learner. Denver: DeLeon Publishing.

Sousa, D. A. (2011). How the Brain Learns (4th ed.). Thousand Oaks, CA: Corwin.

Sperry, R. (1966). Brain bisection and consciousness. In J. Eccles (Ed.), How the self controls its brain. New York: Springer-Verlag.

Squire, L. R. (2004). Memory systems of the brain: A brief history and current perspective. Neurobiology of Learning and Memory, 82, 171-177. https://doi.org/10.1016/j.nlm.2004.06.005

Squire, L. R. (2009). Memory and brain systems: 1969-2009. Journal of Neuroscience, 29(41), 12711-12716. https://doi.org/10.1523/JNEUROSCI.3575-09.2009

Sweeney, M. S. (2009). Brain: The complete mind. Washington, DC: National Geographic.

Sylwester, R. (1998). The Downshifting Dilemma: A Commentary and Proposal. New Horizons for Learning: School of Education, Johns Hopkins University. Retrieved from http://education.jhu.edu/newhorizons/Neurosciences/articles/ 
Tononi, G. (2008). Consciousness as Integrated Information: A Provisional Manifesto. Biological Bulletin, 215(3), 216-242. https://doi.org/10.2307/25470707

Tononi, G., \& Edelman, G. M. (1998). Consciousness and complexity. Science, 282(5395), 1846-1851. https://doi.org/10.1126/science.282.5395.1846

Tulving, E. (1972). Episodic and semantic memory. In E. Tulving, W. Donaldson, \& G. H. Bower (Eds.), Organisation of memory (pp. 381-403). New York: Academic Press.

Tulving, E. (1985). Elements of Episodic Memory. New York: Oxford University Press.

Tulving, E. (2002). Episodic memory: From mind to brain. Annual Review of Psychology, 53, 1-25. https://doi.org/10.1146/annurev.psych.53.100901.135114

Wagner, A. D., Schacter, D. L., Rotte, M., Koutstaal, W., Maril, A., Dale, A. M., ... Buckner, R. L. (1998). Building memories: Remembering and forgetting of verbal experiences as predicted by brain activity. Science, 281, 1188-1191. https://doi.org/10.1126/science.281.5380.1188

Watagodakumbura, C. (2015a). Identifying Sound Pedagogical Practices Based on Findings from Neuroscience. International Journal of Education, 7(2), 146-159. https://doi.org/10.5296/ije.v7i2.7318

Watagodakumbura, C. (2015b). Reflecting on Learner Assessments and their Validity in the Presence of Emerging Evidence from Neuroscience. Higher Education Studies, 5(3), 58-65. https://doi.org/10.5539/hes.v5n3p58

Watagodakumbura, C. (2015c). Reviewing the Purpose of Education and Challenges Faced in Implementing Sound Pedagogical Practices in the Presence of Emerging Evidence from Neuroscience. World Journal of Education, 5(6), 23-36. Retrieved from http://www.sciedu.ca/journal/index.php/wje/article/view/8034

Watagodakumbura, C. (2015d). Some Useful Pedagogical Practices: Educational Neuroscience Perspective. Journal of Studies in Education, 5(4), 191-221. https://doi.org/10.5296/jse.v5i4.8521

Watagodakumbura, C. (2016). Education from a Deeper and Multidisciplinary Perspective-To a Sustainable Development of a Neurodiverse Society - A Futuristic View. USA: Book Venture.

Webb, J. T. (2008). Dabrowski's Theory and Existential Depression in Gifted Children and Adults. Paper presented at the Eighth International Congress of the Institute for Positive Disintegration in Human Development, Alberta, Canada.

Webb, J. T., Amend, E. R., Webb, N. E., Goerss, J., Beljan, P., \& Olenchak, F. R. (2005). Misdiagnosis and Dual Diagnoses of Gifted Children and Adults: ADHD, Bipolar, Ocd, Asperger's, Depression, and Other Disorders. USA: Great Potential Press.

Yero, J. (2002). How Teacher Thinking Shapes Education. In New Horizons for Learning. School of Education, Johns Hopkins University. Retrieved from http://education.jhu.edu/PD/newhorizons/Neurosciences/articles/

Yzerbyt, V. Y., Lories, G., \& Dardenne, B. (Eds.). (1998). Metacognition: Cognitive and social dimensions. Thousand Oaks: Sage Publications.

\section{Copyrights}

Copyright for this article is retained by the author(s), with first publication rights granted to the journal.

This is an open-access article distributed under the terms and conditions of the Creative Commons Attribution license (http://creativecommons.org/licenses/by/4.0/). 